\title{
Performance Evaluation of a Nine-Phase Synchronous Reluctance Drive
}

\author{
C.E. Coates ${ }^{*}$, D. Platt ${ }^{* *}$ and V.J. Gosbell ${ }^{* *}$ \\ * Department of Electrical and Computer Engineering \\ University of Newcastle, NSW 2308, Australia \\ Tel.: +61 24921 8969, Fax.: +61 24921 6993, E-mail: colin@ecemail.newcastle.edu.au \\ ** School of Electrical, Computer and Telecommunications Engineering \\ University of Wollongong, NSW 2522, Australia
}

\begin{abstract}
This paper describes the performance of an experimental $5 \mathrm{~kW}$ nine-phase synchronous reluctance motor (Syncrel) drive. Increasing the number of phases of the Syncrel above three allows the stator MMF's to be shaped, producing significantly greater torque / RMS ampere in the same volume machine. Generalized d-q voltage and torque equations are derived for the nine-phase Syncrel. These demonstrate that harmonic direct and quadrature components of current contribute to torque production in the machine and can be controlled by applying appropriate stator voltages. A fieldoriented controller is described and implemented using a TMS320C32 digital signal processor board. The controller designates portions of the stator winding as supplying either direct or quadrature excitation. A simple inverter switching strategy is used to control the phase currents to their reference values. Experimental current regulation, speed response and torque measurements are presented from the drive. These results validate the system model and demonstrate the drive capability.
\end{abstract}

\section{INTRODUCTION}

The synchronous reluctance motor (Syncrel) continues to gain increasing research interest as an alternative to the ac induction motor drive [1-9]. Advantages of the Syncrel include its simple rugged rotor structure, comparatively low rotor inertia, high torque density and the absence of rotor windings leading to reduced losses.

The rotor saliency of the Syncrel produces a "rectangular" air-gap flux density distribution. If a rectangular stator current distribution interacts with this flux the motor generates its optimal torque. This conjecture is supported by recent work that demonstrates that the torque / RMS ampere for a given volume machine can be raised by adding a third harmonic component to the stator MMF distribution [4, 7]. The idea is carried to its logical conclusion by assuming a motor is excited by the "ideal" rectangular stator current distribution during the design process. A $5 \mathrm{~kW}$ axially laminated machine has been designed and built on this assumption [2]. This machine is demonstrated to produce between 1.5 to 2 times the torque output of a similarly sized induction motor. It has a nine-phase concentrated stator winding to approximate the ideal stator current distribution. Other dimensions for the $5 \mathrm{~kW}$ machine are summarized in Appendix A. This paper presents two field-oriented control strategies for the nine-phase Syncrel and evaluates the dynamic performance of the drive.
To date, there has only been a limited number of experimental multi-phase Syncrel drives reported in the literature. Law et. al. design and implement a six-phase field regulated reluctance machine having established the theoretical capability for it to produce $68 \%$ greater force density than a comparable induction machine [5]. In this experimental machine, each phase winding is isolated and supplied from a separate full-bridge inverter.

In two other instances research has focused on introducing an additional third harmonic component to the fundamental MMF wave. Hsu et. al. add a third harmonic component using a dual three-phase machine with six isolated phase windings [4]. Toliyat et. al. demonstrate that the same result can be achieved using a five-phase star connected stator supplied from a standard voltage source inverter [7]. This effectively minimizes the number of power electronic devices required to control the third harmonic component of the MMF wave. The same argument is applied here in proposing the nine-phase star connected winding supplied from a voltage source inverter.

To implement speed and current control on a multi-phase Syncrel drive presents some difficulties. One strategy has been developed for controlling the five-phase Syncrel [9]. However, this controller only regulates the fundamental components of direct and quadrature excitation losing the potential advantage of additional torque production through controlled third harmonic excitation. Two methods of fieldoriented control are proposed here. These regulate the phase currents to their optimal values to ensure full benefit from the nine-phase structure is achieved.

\section{GENERALIZED EQUATIONS}

To model and control the experimental motor's performance requires the initial determination of appropriate voltage and torque equations. The key to obtaining these expressions is the formation of a stator inductance matrix. Traditionally, approximations are made to the stator winding distribution and air-gap length as functions of angular displacement around the stator. These expressions are then used to determine the inductance values including the necessary harmonic components [6,8]. This approach becomes cumbersome as it becomes necessary to include higher order harmonic components in the calculation. 
An alternative approach is to approximate the air-gap flux density distribution and hence determine flux linkages [3]. This method significantly simplifies the necessary calculations. It can be used to show the mutual inductance between two fully pitched, concentrated stator coils (separated by $\beta$ radians) as a function of rotor position, $\alpha$, is,

$$
\begin{array}{r}
M_{a b}(\alpha)=\frac{4}{\pi^{2}}\left(L_{d}-L_{q}\right) \sum_{n=1(\text { odd })}^{\infty} \frac{\cos (n(2 \alpha+\beta))}{n^{2}} \\
+\frac{4}{\pi^{2}}\left(L_{d}+L_{q}\right) \sum_{n=1(\text { odd })}^{\infty} \frac{\cos (n \beta)}{n^{2}} .
\end{array}
$$

$L_{d}$ and $L_{q}$ are the inductances seen when the axis of a stator phase winding is aligned with the rotor direct and quadrature axes respectively.

The stator inductance matrix, $\boldsymbol{L}(\alpha)$, can be formed given the specific dimensions of the nine-phase machine. The matrix is symmetrical and a transformation matrix, $\boldsymbol{T}(\alpha)$, can be found such that the orthogonal transformation, $\boldsymbol{T}(\alpha) \boldsymbol{L}(\alpha) \boldsymbol{T}^{T}(\alpha)$, yields a diagonal matrix whose diagonal elements are,

$$
\begin{array}{cc}
L_{d 1}=\frac{36}{\pi^{2}} L_{d} & L_{q 1}=\frac{36}{\pi^{2}} L_{q} \\
L_{d 3}=\frac{4}{\pi^{2}} L_{d} & L_{q 3}=\frac{4}{\pi^{2}} L_{q} \\
L_{d 5}=\frac{36}{25 \pi^{2}} L_{d} & L_{q 5}=\frac{36}{25 \pi^{2}} L_{q} \\
L_{d 7}=\frac{36}{49 \pi^{2}} L_{d} & L_{q 7}=\frac{36}{49 \pi^{2}} L_{q}
\end{array}
$$

These elements correspond to the fundamental, third, fifth and seventh harmonic, direct and quadrature components of stator inductance.

The transformation matrix can also be applied to the standard stator voltage equation to determine the $\mathrm{d}-\mathrm{q}$ voltage equations in harmonic component form. These equations are;

$$
\begin{aligned}
& v_{d 1}=r_{s} i_{d 1}+L_{d 1} \frac{d i_{d 1}}{d t}+2 L_{q 1} \omega i_{q 1}, \\
& v_{q 1}=r_{s} i_{q 1}+L_{q 1} \frac{d i_{q 1}}{d t}-2 L_{d 1} \omega i_{d 1}, \\
& v_{d 3}=r_{s} i_{d 3}+L_{d 3} \frac{d i_{d 3}}{d t}+6 L_{q 3} \omega i_{q 3}, \\
& v_{q 3}=r_{s} i_{q 3}+L_{q 3} \frac{d i_{q 3}}{d t}-6 L_{d 3} \omega i_{d 3}, \\
& v_{d 5}=r_{s} i_{d 5}+L_{d 5} \frac{d i_{d 5}}{d t}+10 L_{q 5} \omega i_{q 5}, \\
& v_{q 5}=r_{s} i_{q 5}+L_{q 5} \frac{d i_{q 5}}{d t}-10 L_{d 5} \omega i_{d 5}, \\
& v_{d 7}=r_{s} i_{d 7}+L_{d 7} \frac{d i_{d 7}}{d t}+14 L_{q 7} \omega i_{q 7},
\end{aligned}
$$

$$
v_{q 7}=r_{s} i_{q 7}+L_{q 7} \frac{d i_{q 7}}{d t}-14 L_{d 7} \omega i_{d 7} .
$$

where,

$v_{d n}=\mathrm{n}$ 'th harmonic direct comp. of stator voltage (V),

$v_{q n}=\mathrm{n}$ 'th harmonic quadrature comp. of stator voltage $(\mathrm{V})$,

$i_{d n}=$ n'th harmonic direct comp. of stator current (A),

$i_{q n}=$ n'th harmonic quadrature comp. of stator current (A),

$r_{s}=$ stator phase winding resistance $(\Omega)$,

$\omega=$ rotor speed $(\mathrm{rad} / \mathrm{s})$.

Note that the stator winding of the experimental Syncrel is star connected with no neutral. As such there are only eight independent stator phase currents and no zero sequence component. Only eight transformed variables are required to describe the system.

The corresponding d-q torque expression can be determined by considering the change in system co-energy with respect to rotor position. The torque equation is,

$$
\begin{aligned}
T_{e}= & 2\left(L_{d 1}-L_{q 1}\right) i_{d 1} i_{q 1}+6\left(L_{d 3}-L_{q 3}\right) i_{d 3} i_{q 3} \\
& +10\left(L_{d 5}-L_{q 5}\right) i_{d 5} i_{q 5}+14\left(L_{d 7}-L_{q 7}\right) i_{d 7} i_{q 7} .
\end{aligned}
$$

The torque equation indicates that the harmonic direct and quadrature components of current contribute to torque production in the Syncrel. The voltage equations suggest the possibility of controlling the harmonic components of current with appropriate stator voltages.

\section{CONTROL STRATEGY}

Field-oriented control involves separately controlling the direct and quadrature axis excitations in the motor. Different strategies can be used to achieve such goals as maximum torque, maximum rate of change of torque and maximum power factor [1]. Here a "constant current in the inductive axis" type controller is implemented. Fig. 1 shows a simplified block diagram of this controller. Direct axis excitation is held at a constant value to maintain machine

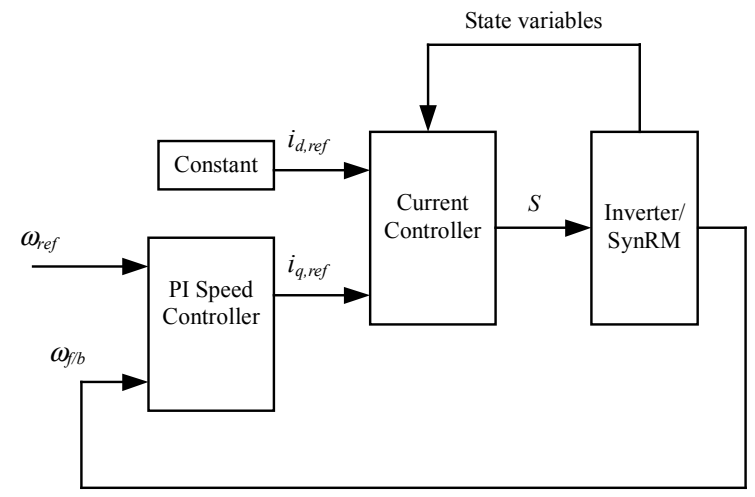

Fig. 1. Simplified block diagram of Syncrel controller using "constant current in the inductive axis" type control. 
flux. Quadrature axis excitation is varied to control the motor torque. The control methods presented here are essentially means to implement the current controller block in Fig. 1. They take the nominal direct and quadrature axis excitation values and determine the appropriate inverter switching configuration in any given control cycle.

Two strategies are considered. The first is based on a simple switching strategy in the stator current plane. The second attempts to find the optimal inverter-switching configuration in the transformed d-q harmonic planes.

\section{A. Stator Current Controller}

The stator current controller "splits" the stator winding into two sections similar to the original design model. Phase windings located over the rotor pole edges carry direct axis current. The windings located over the rotor pole face carry quadrature axis current. By knowing the rotor position and its dimensions the appropriate phase current references can be generated. A similar strategy has been used to control the field regulated reluctance machine previously discussed [5]. Here the strategy is applied to a star connected winding fed from a voltage source inverter eliminating half of the power electronic devices required in the equivalent field regulated reluctance machine.

Generating the stator current reference is complicated by two practical constraints. First, stator current is not continuously distributed but is concentrated in the stator slots. Step changes in the stator current can only be made at a slot opening. As the rotor moves individual phase windings at either edge of the rotor pole face must make a transition from supplying purely direct axis excitation to purely quadrature axis excitation or vice versa. Thus, the current reference is not square but is instead trapezoidal.

Further, the stator phase winding is star connected. The individual phase currents must sum to zero. To aid in achieving this requirement adjacent phase windings on the stator have their connection polarities reversed. Consequently, the current direction is also reversed ensuring adjacent phase currents still physically pass in the same direction through the slot where required. Given the $5 \mathrm{~kW}$ machine dimensions, typically one phase supplies the direct axis excitation, while the other eight phases supply quadrature excitation. Since adjacent phases are reversed, the eight quadrature current phases will conveniently sum to zero. A fraction of the current reference from the ninth phase, that supplies direct axis excitation, must be subtracted from each of the other eight phases so that all nine phase currents sum to zero.

Fig. 2 shows a typical current reference for one stator phase of the $5 \mathrm{~kW}$ machine. The current reference is plotted against rotor position. Compensation for both stator slotting effects and the stator winding connection are included in the current reference. For comparison, the ideal current reference assumed in the design model is also shown.

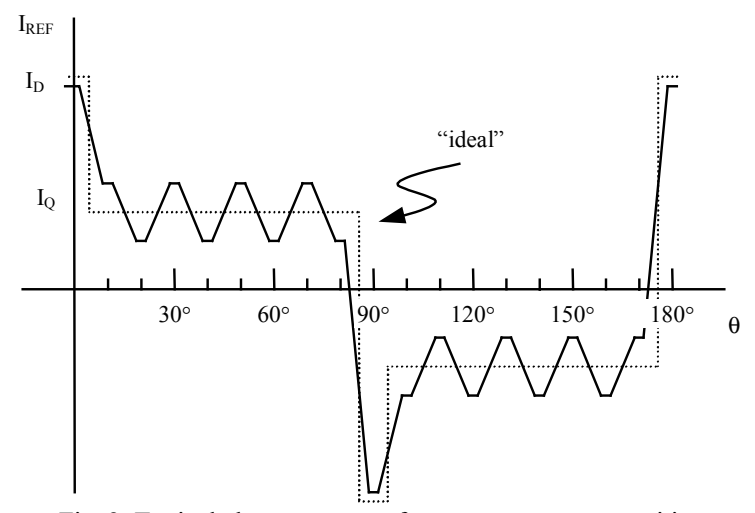

Fig. 2. Typical phase current reference versus rotor position

The stator current controller reads rotor position and generates the appropriate current references for the nine motor phases. Individual phase windings are then switched to either the positive or negative inverter bus depending on the phase current relationship to the reference.

\section{B. Transformed Frame Controller}

Selecting the optimal inverter switching configuration in the transformed $d-q$ current planes offers potential improvements over the stator current controller. Stator currents and voltages are considered as transformed variables in the d-q harmonic planes. Thus, any one phase winding's contribution to both direct axis or quadrature axis excitation is recognized rather than the simplified designation of the stator current controller. A current reference is generated as a vector in the harmonic planes where a voltage vector can be applied, via the inverter, to control the current feedback vector's position.

The current reference is generated from the harmonic components of the ideal, design model current distribution shown in Fig. 2. These components are found by performing a Fourier series decomposition. Fig. 3 shows the current reference vectors for the transformed frame controller thus formed. Effectively, the reference becomes a set of stationary vectors in the rotor current plane whose lengths have a simple proportional relationship to what is designated direct and quadrature axis current in the design model.

Selecting the optimal inverter switching configuration, or voltage vector, to be applied during a control cycle is a significant problem. In a three phase induction motor drive this is equivalent to the familiar choice from $2^{3}=8$ ( 7 distinct) two dimensional voltage vectors. For the nine-phase drive this becomes a choice from $2^{9}=512$ (511 distinct) eight dimensional voltage vectors.

The choice is further complicated by the different inductances seen in the direct and quadrature axes as well as the different harmonic planes. In an induction motor drive the choice can be made by calculating the ideal voltage vector, $v_{\text {ideal }}$, and comparing it to the possible voltage vectors. $v_{\text {inv }}(S)$ (where $s$ denotes the inverter switching configuration). 

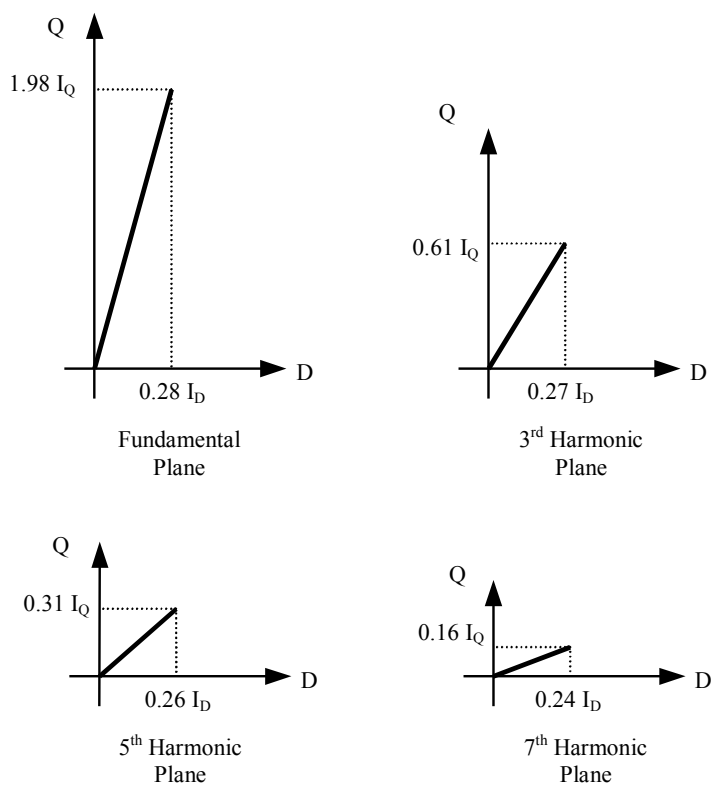

Fig. 3. Syncrel current reference in transformed rotor current plane.

The optimal voltage vector is found by minimizing the error, $v_{i n v}(S)-v_{\text {ideal }}$. This method works where all inductances are equal because the error in the current plane is proportional to the error in the voltage plane.

For the Syncrel, it has been shown that the inductance associated with each direct and quadrature harmonic component is different. To correctly relate voltage error to current error the individual components must be scaled. The scaling function for voltage error is,

$$
\begin{aligned}
& \left(v_{\text {inv }}(s)-v_{\text {ideal }}\right)^{\prime}=\left(v_{\text {inv }}(s)-v_{\text {ideal }}\right) \times \\
& \left(\begin{array}{ccccccccc}
\frac{L_{q}}{L_{d}} & 0 & 0 & 0 & 0 & 0 & 0 & 0 & 0 \\
0 & 1 & 0 & 0 & 0 & 0 & 0 & 0 & 0 \\
0 & 0 & \frac{9 L_{q}}{L_{d}} & 0 & 0 & 0 & 0 & 0 & 0 \\
0 & 0 & 0 & 9 & 0 & 0 & 0 & 0 & 0 \\
0 & 0 & 0 & 0 & \frac{25 L_{q}}{L_{d}} & 0 & 0 & 0 & 0 \\
0 & 0 & 0 & 0 & & 25 & 0 & 0 & 0 \\
0 & 0 & 0 & 0 & 0 & 0 & \frac{49 L_{q}}{L_{d}} & 0 & 0 \\
0 & 0 & 0 & 0 & 0 & 0 & 0 & 49 & 0 \\
0 & 0 & 0 & 0 & 0 & 0 & 0 & 0 & 0
\end{array}\right)
\end{aligned}
$$

To implement the transformed frame controller the motor phase currents, speed and position are read. The phase currents are transformed to the corresponding current vector in the $\mathrm{d}-\mathrm{q}$ harmonic planes by multiplying by the transformation matrix, $\boldsymbol{T}(\alpha)$. The ideal voltage required to maintain the current reference at its desired value is calculated using the generalized voltage equations (2-9). The inverter switching configuration is then determined by choosing the best voltage vector on the basis of scaled voltage error.

\section{Simulation Results}

Initial testing and comparison of the two controllers was performed through simulation in MATLAB ${ }^{\circledR} /$ Simulink $^{\circledR}$. Fig. 4 shows the simulated step torque response for both controllers. Both simulations were carried out assuming a $5 \mathrm{kHz}$ control cycle. The transformed frame controller can be seen to offer faster response as well as better torque regulation.

Although the transformed frame controller offers significantly improved performance it still presents some difficulty to implement. The calculation overhead for the voltage vector selection process is quite large. Most significantly, the controller is required to transform the motor currents and select the best voltage vector within a control cycle. These functions could not be implemented in software with sufficient speed. A potential solution is to do the current transformation in hardware and use symmetries amongst the voltage vectors to reduce the number of vectors required in the comparison. Due to these difficulties only the stator current controller has been implemented in the experimental drive to date.

(a)

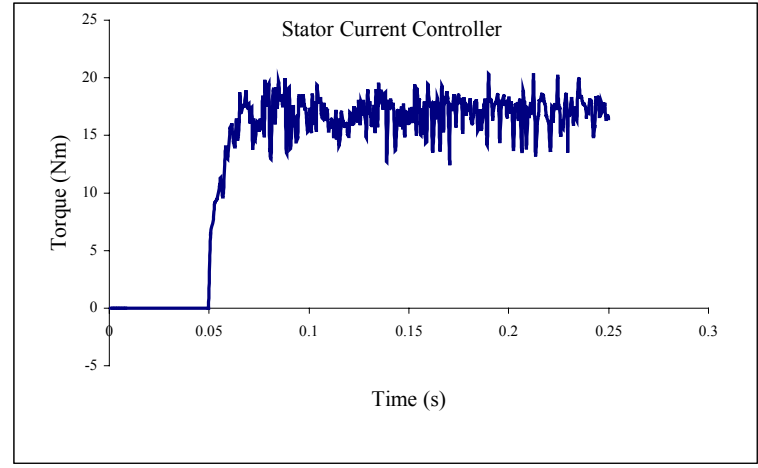

(b)

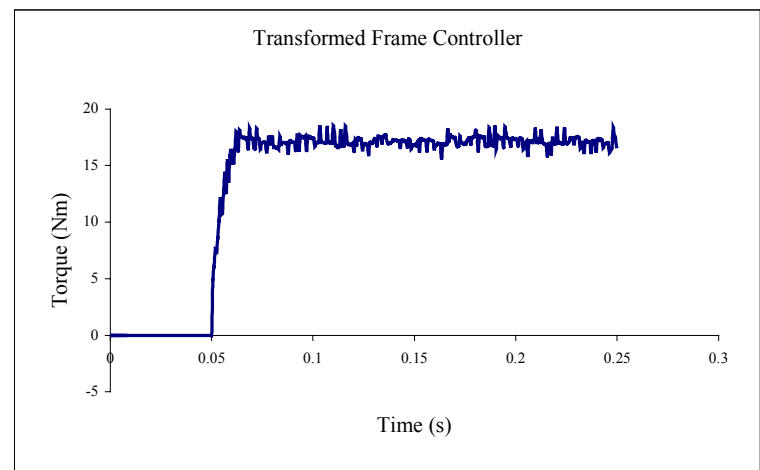

Fig. 4. Step torque response of (a) stator current controller and (b) transformed frame controller 


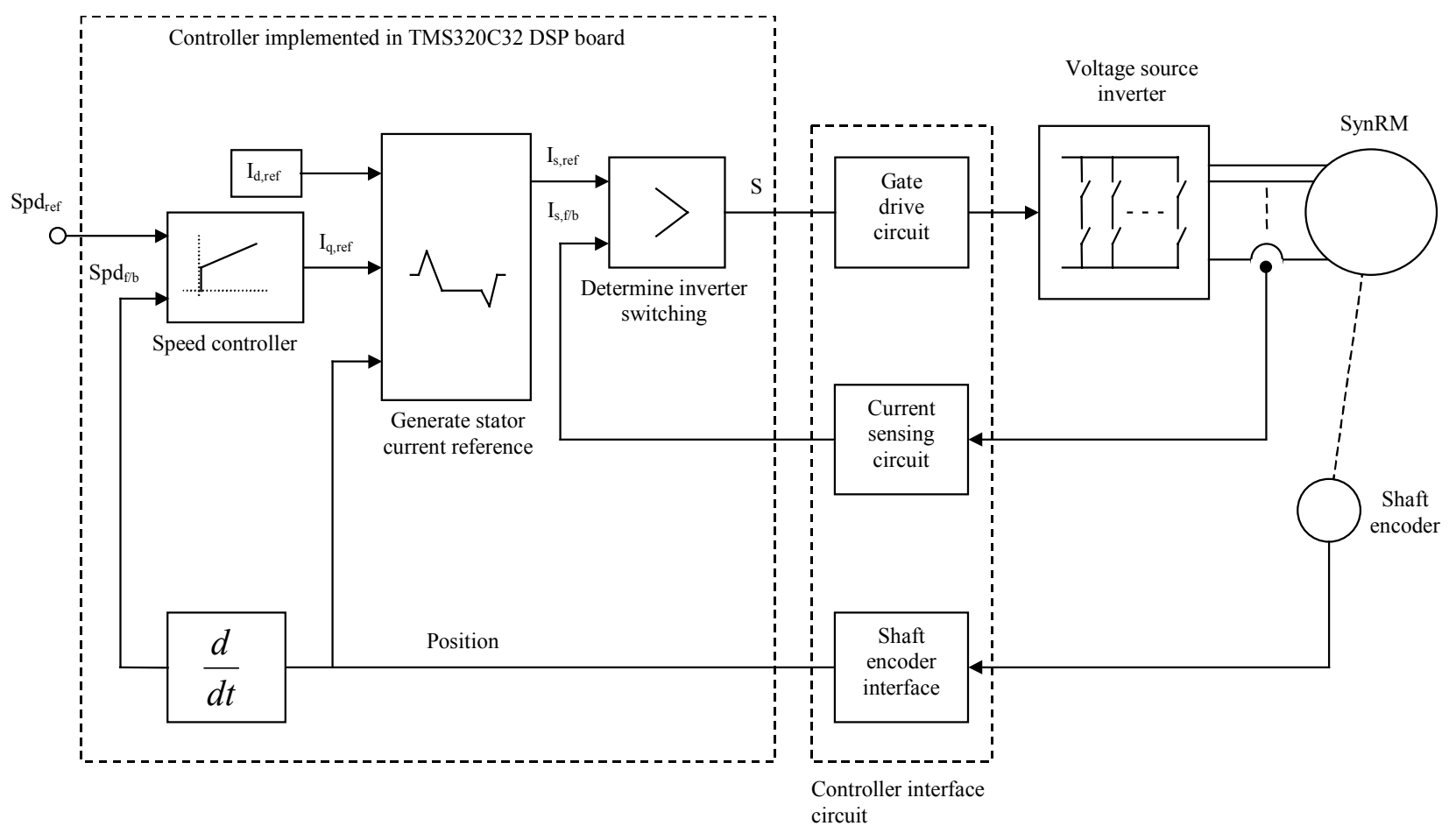

Fig. 5. Block diagram of drive system hardware

\section{DRIVE HARDWARE}

Fig. 5 shows an overview of the hardware used to implement the stator current controller on the experimental Syncrel as well as a functional diagram of the controller. The power circuit is that of a typical voltage source inverter. A diode rectifier and $\mathrm{LC}$ filter convert the ac mains to a dc bus voltage. A nine-leg inverter then converts the dc bus voltage to the nine-phase supply required by the Syncrel. Dynamic braking is included to limit the bus voltage during regenerative operation of the drive.

The drive is controlled by an Innovative Integration ADC64 DSP card. This card contains a $60 \mathrm{MHz}$ TMS320C32 processor along with the appropriate support peripherals. Interfacing circuitry between the controller and power circuit can be functionally divided into gate drive, current sensing and shaft encoder interface circuitry. The gate drive circuitry provides isolation between the controller and power circuit as well as hardware based anti-shoot through protection. Current sensing is performed using Hall effect devices in eight of the motor phases. These are read through $200 \mathrm{kHz}$ A/D converters on the ADC64 card. Position and speed feedback are obtained from a three channel, 1000 pulse per revolution optical encoder. Two channels in quadrature drive a counter and provide up/down logic corresponding to forward/reverse direction. The third channel provides a synchronization pulse once per revolution.

The controller itself regulates the nominal direct and quadrature axis excitations in the motor. Direct axis excitation is controlled to a constant value that maintains machine magnetic flux. Quadrature axis excitation is varied to adjust the machine's torque output. A PI speed controller generates the quadrature current reference. The nominal direct and quadrature current references combined with the rotor position are used to generate a set of phase current reference values. These are compared with the phase current feedback values and an appropriate inverter switching configuration determined.

\section{RESUlts}

The stator current controller was implemented as detailed. Fig. 6a shows a typical phase current waveform recorded at low motor speed. The direct axis excitation is set to $1.8 \mathrm{~A}$, the value required to fully flux the experimental machine. Quadrature axis excitation is set by the speed loop to the value necessary to maintain the speed of the unloaded motor. In Fig. 6 the direct and quadrature components of current can be clearly recognized along with the adjustments made for stator slotting and the winding connection.

Fig. $6 \mathrm{~b}$ shows a phase current waveform recorded at higher motor speed. In this instance the shape of the waveform begins to diverge from the ideal reference. Most notably the size and shape of the direct axis excitation portion of the waveform begins to reduce. At higher speeds the induced voltage in the stator winding increases, lowering the voltage available to drive the phase currents to the desired levels. This mechanism imposes an upper speed limit on the drive. Beyond a point reduced direct axis excitation will lower the flux in the machine and reduce the available torque. 
(a)

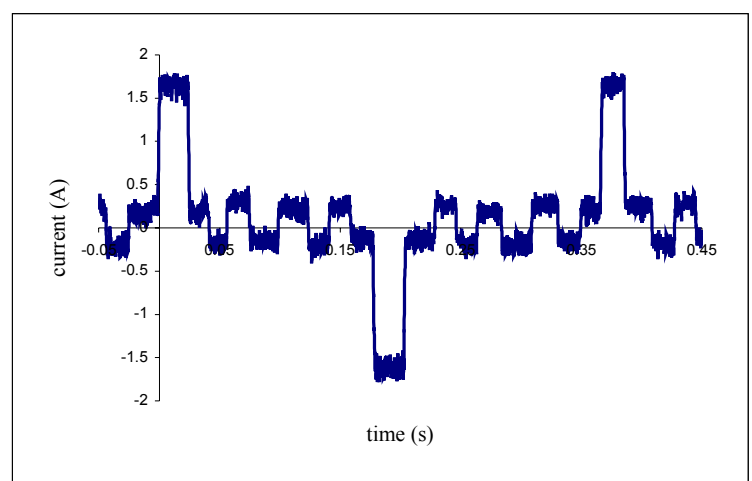

(b)

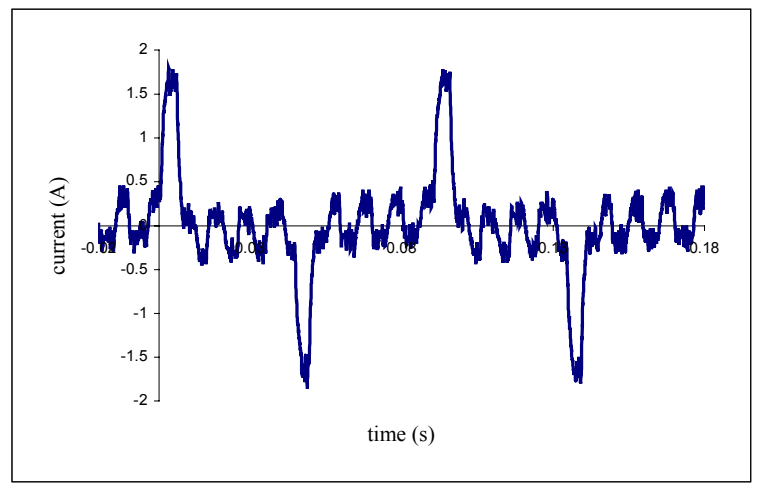

Fig. 6. Measured phase current in Syncrel under stator current control where (a) $\omega=80 \mathrm{rpm}$ and (b) $\omega=345 \mathrm{rpm}$ (inverter bus voltage $=250 \mathrm{~V}$ ).

Fig. 7 shows the shows the speed and quadrature current values recorded in response to a step change in speed reference at time zero. Included in the figure are simulation results based on the generalized equations for the machine. Close correlation can be observed between the simulated and measured values. Particularly, the rise time for the speed response and the amplitude of the quadrature current pulse match in simulation and practice. One notable difference between the simulated and experimental systems is the steady state quadrature current value. The simulation does not include mechanical losses, such as friction, so the steady state quadrature current is shown to be zero amps.

Fig. 8 shows a graph of torque versus quadrature current measured with the Syncrel operating at various speeds. The measurements were made by coupling the Syncrel to a dc drive. The dc drive was used to set the system speed. While the machines were operating at a constant speed the quadrature current set point for the Syncrel was adjusted. Actual shaft torque from the Syncrel was measured using a torque transducer mounted at the coupling between the machines.

Examining Fig. 8 at low speeds shows that a linear relationship is maintained between Syncrel torque and quadrature axis current. This result is predicted by the Syncrel torque equation (10) where direct axis excitation is held constant. As Syncrel speed is increased the available (a)

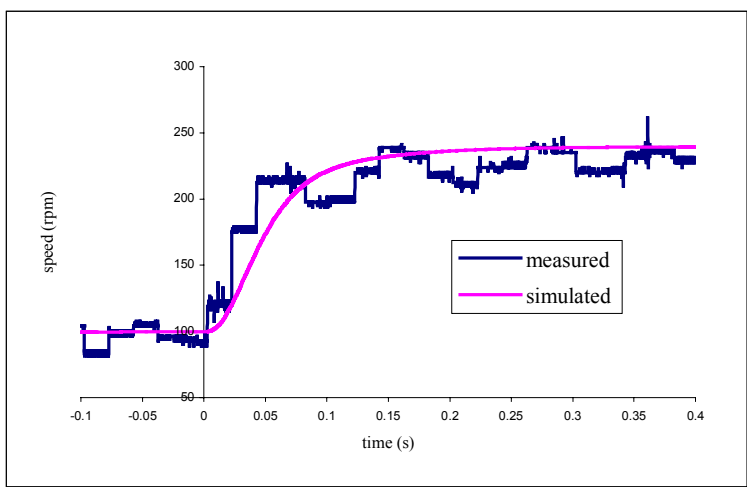

(b)

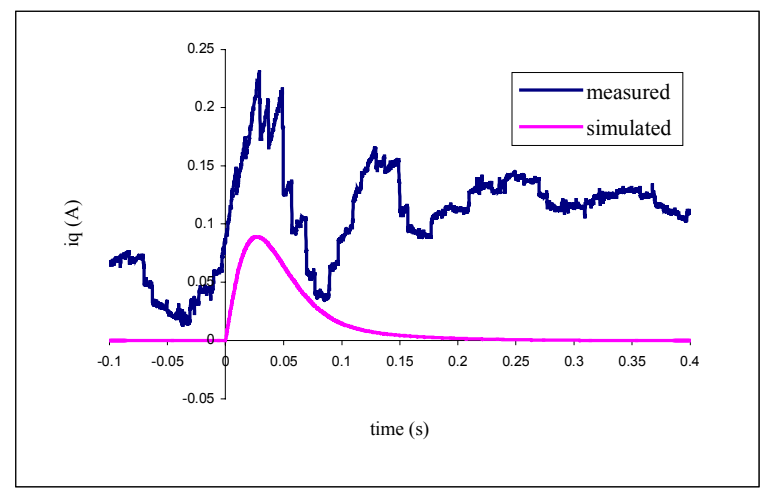

Fig. 7. Measured and simulated (a) speed and (b) quadrature current values in response to a step change in speed reference from $100 \mathrm{rpm}$ to $240 \mathrm{rpm}$.

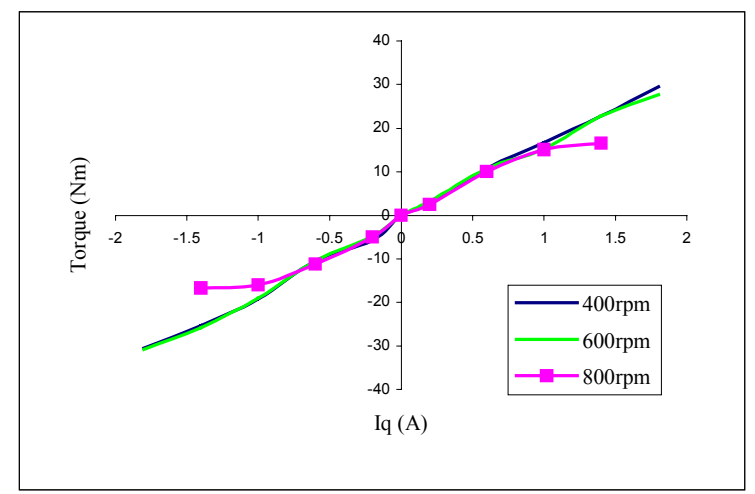

Fig. 8. Torque versus quadrature current for Syncrel

torque begins to reduce at higher quadrature current values. Examination of the phase current waveforms indicates that the loss in torque coincides with a loss in the direct axis current portion of the current waveform. Essentially the increased speed voltage in the winding means that there is insufficient inverter voltage to drive the direct axis currents. The drive could be made to operate at higher speeds by appropriately reducing the number of turns in the phase windings and hence lowering the speed voltage. 


\section{CONCLUSIONS}

A nine - phase Syncrel drive has been developed and tested. The key advantage of this drive is that it maximizes the available torque from the Syncrel structure. Field-oriented type control has been implemented using a simple stator current control strategy. This strategy was found capable of regulating current, speed and torque. In addition, the strategy is simple enough that it can be implemented without a heavy processing requirement in the controlling device.

An alternative field-oriented controller has also been investigated. The generalized voltage and torque equations suggest the possibility of implementing a controller in the transformed current and voltage variables. This controller is termed the transformed frame controller. Simulation results suggest that the controller offers faster torque response and better torque regulation. However, the computational requirement makes it difficult to implement. Suggestions have been made on means to implement the controller but these remain unverified in practice.

\section{APPENDIX}

\section{A. $\quad 5 \mathrm{~kW}$ Syncrel Dimensions}

$\begin{array}{ll}\text { Number of poles } & =4 \\ \text { Rotor pole pitch } & =1.44 \text { radians } \\ \text { Rotor radius } & =64 \mathrm{~mm} \\ \text { Rotor Length } & =51 \mathrm{~mm} \\ \text { Rotor steel : steel }+ & \text { fibre ratio }=0.45 \\ \text { Air-gap } & =0.3 \mathrm{~mm} \\ \text { Number of slots } & =36 \\ \text { Number of phases } & =9 \\ \text { Yoke depth } & =20 \mathrm{~mm} \\ \text { Slot depth } & =22 \mathrm{~mm} \\ \text { Slot opening } & =0.6 \mathrm{~mm}\end{array}$

\section{REFERENCES}

[1] R.E. Betz, "Theoretical aspects of control of synchronous reluctance machines", IEE Proceedings - $B$, volume 139, number 4, pages 355-364, July 1992.

[2] C.E. Coates, D. Platt and B.S.P. Perera, "Design optimization of an axially laminated synchronous reluctance motor", Conference Record of IEEE-IAS Annual Meeting 1997, volume 1, pages 279-285.

[3] C.E. Coates, D. Platt and V.J. Gosbell, "Generalized equations for a nine phase synchronous reluctance motor", Australian Universities Power Engineering Conference 1996, volume 1, pages 43-48.

[4] J.S. Hsu (Htsui), S.P. Liou and H.H. Woodson, "PeakedMMF smooth torque reluctance motors", IEEE Trans. on Energy Conversion, volume 5, number 1, pages 104109, March 1990.

[5] J.D. Law, A. Chertok and T.A. Lipo, "Design and performance of field regulated reluctance machine" IEEE Transactions on Industry Applications, volume 30, number 5, pages 1185-1191, September / October 1994.

[6] P.J. Lawrenson and L.A. Agu, "Theory and performance of polyphase reluctance machines", Proceedings of IEE, volume 111, number 8, pages 1435-1445, August 1964.

[7] H.A. Toliyat, M.M. Rahimian and T.A. Lipo, "A five phase reluctance motor with high specific torque", IEEE Transactions on Industry Applications, volume 28, number 3, pages 659-667, May/June 1992.

[8] H.A. Toliyat, M.M. Rahimian and T.A. Lipo, "dq modelling of a five phase synchronous reluctance machine including third harmonic of air-gap MMF", Conference Record of IEEE - IAS Annual Meeting 1991, volume 1, pages 231-237.

[9] H.A. Toliyat, R. Shi and H. Xu, "A DSP based vector control of five-phase synchronous reluctance motor", Conference Record of IEEE - IAS Annual Meeting 2000, volume 3 , pages 1759-1765 